

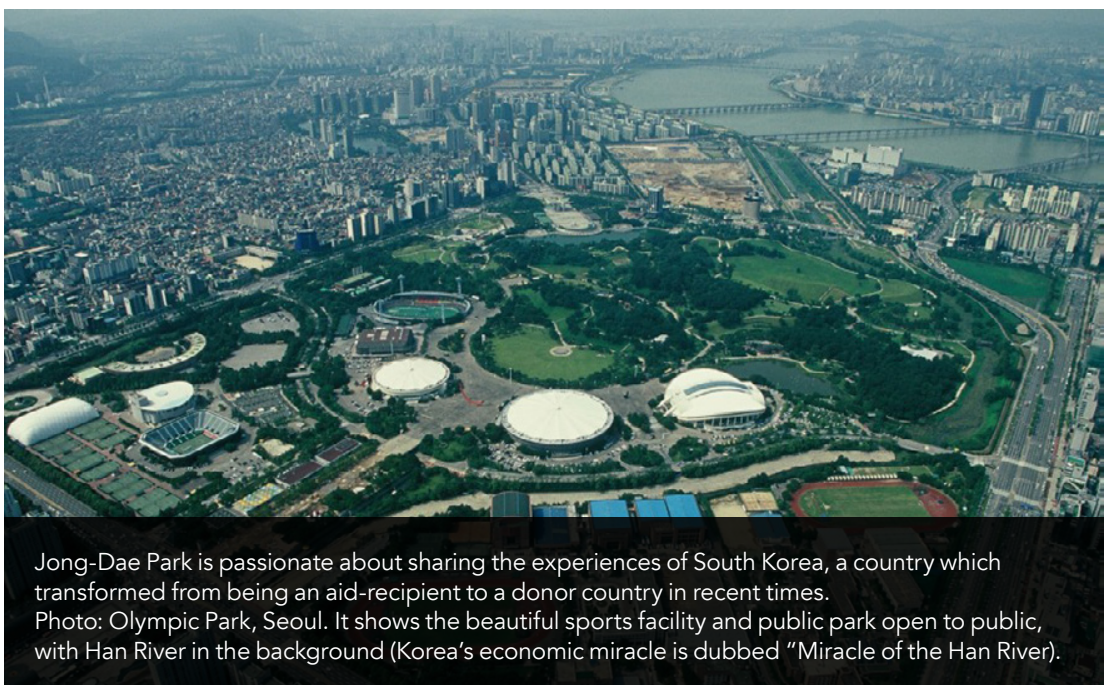

What is also missing in the equation of aid for Africa's development is reciprocity between donors and recipients.

why a recent study from $U$ gs possibly

dicates that while the governmental

elites prefer direct budget support, the

mass of people prefer the donors to be in control. Meanwhile, projects more tightly controlled by donors are often un by experts who seem to have little dea of what they are doing, and take title heed of the opinions or actual eeds of the local populace.

To provoke logical thinking, Dr JongDae Park, South Korean Ambassadd in South Africa, often asks elite Africans "Who is to blame? Donors as the recipients' ability to use it. In essence, aid is just a means to an end, has good intentions, and it is naive and irrational to expect that things will get better if aid is rejected or replaced by investments and business.

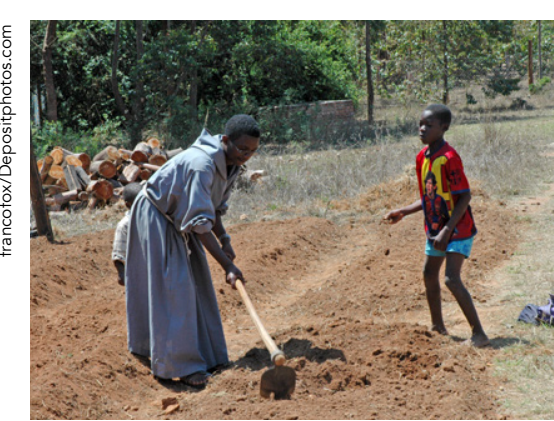

INHERENT LIMITATIONS

OF FOREIGN AID

Sub-Saharan Africa's woes are not

caused by aid, but by all the negative

elements and inherent problems

existing in the countries, most

lack of developmental mind-set. The

perception that what only matters is

what donors do is simply wrong and

detrimental to Africa's development

because the biggest hurdle is the

issue of ownership, which is also linked

Whereas humanitarian aid or disaster relief have very easy and clear cut

recipient, developmental aid is far more

complicated. Cultural differences and

misunderstandings can cause great

difficulties in completing these kinds of large-scale construction or infrastructure projects, and when "ownership" of

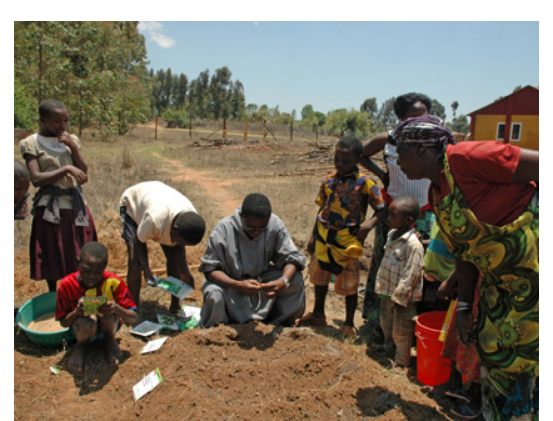

Sel-sustaining project of the Franciscan Friars of the Pomerini Village, Tanzania. hese is passed on to the recipients, the he recipients kkills to sustain them, or a feeling of responsibility for something they

not create. The handover of a project is not "job done" unless ownership and management of it is successfully completed, with the appropriate skilled management in place, and the ability for it to run independently.

One of the most widespread and undamental misunderstandings is that wealth or development can be achieved by transfers of resources, when it is actually through production or creation of economic values that this is attaine dilemma of aid spe. Then there is dicm the expertise or specialisation in teepen field of development which causes the problem of over compartmentalisation, where the left hand doesn't know what the right is doing. This is exacerbated by the increase in the number of donor organisations over time, many of whom are working in the same regions or fields.

\section{THE ISSUE OF}

ECIPROCAL COMPLIANCE

Dr Jong-Dae Park also points out that

what is also missing in the equation

of aid for Africa's development is

reciprocity between donors and

recipients. At the moment there is an asymmetrical relationship at best, with donor's incomprehension of the region's national interest) on (one hand and the corrulion and dente of the recipient state on the other. The two sides must reciprocate, understand each other, and work together as two businesses might. If either side fails to do this, to have an equal level of compliance with the other, the aid has failed. He makes the case that this compliance gap, both quantitative and qualitative, between donors and African countries must be narrowed in order to make aid programs more effective and meaningful. However, Pr Jong-Dae Park concludes that the onus must be on the recipients There is a saying [in Africal that is ineffective, and where there is governance, aid is unnecessary."

\section{Behind the Research}

— Dr Jong-Dae Park

E: jongdmspark@hanmail.net E: jdpark91@mofa.go.kr T: +27 (0)83 2692009 (mobile)

\section{Research Objectives}

A specialist in African development, Jong-Dae Park is passionate about sharing the experiences of the trom being an aid-recipient to a donor country in a dramatic fashion in recent times.

\section{Detail}

Jong-Dae Park

Embassy of the Republic of Korea

265 Melk Street

Pretoria 0181, South Africa

Bio

Jong-Dae Park is the South Korean Ambassador in South Africa and a specialist in African Development. Formerly Director of Policy Planning of Foreign Ministry, served in the Presidential Office. He holds a BA from Yonsei University, Korea, an MA from UC Berkeley, USA and a PhD from Kyungnam University, Korea.

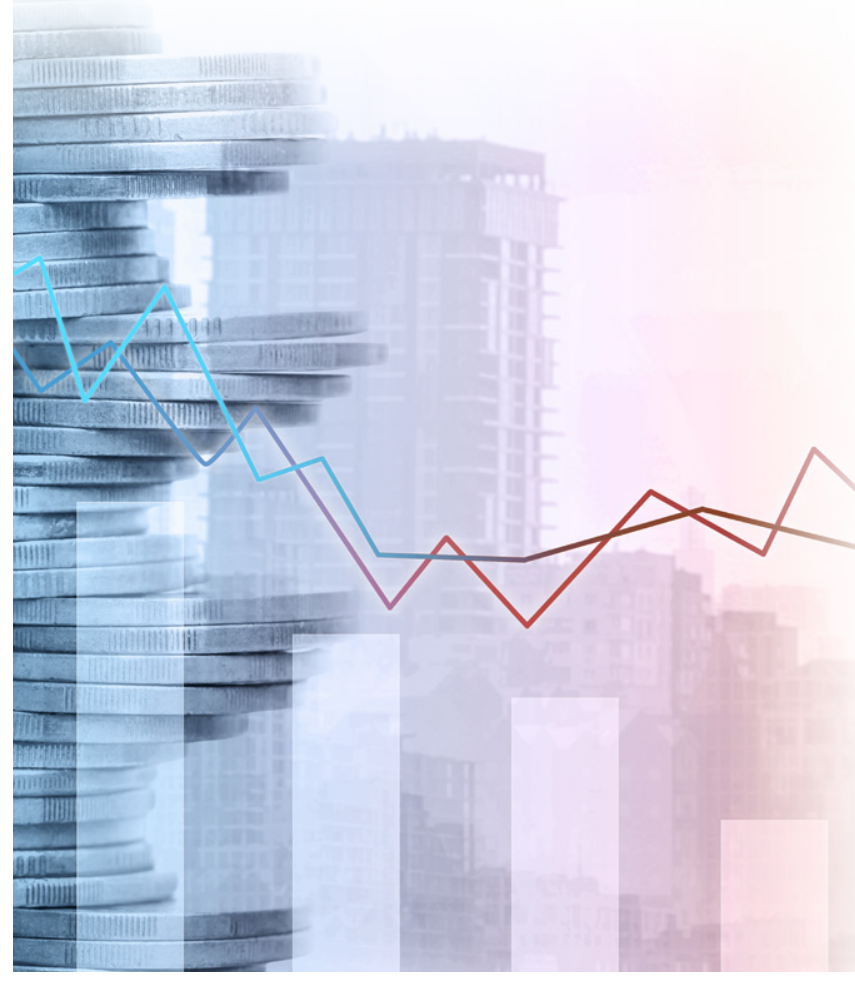

\section{References}

Park, Jong-Dae (2019) Re-inventing Africa's development. Linking Africa to the Korean development model. (Springer Link) http://hdll.handle.net/10419/191568

Andrei Schleifer, 'Peter Bauer and the Failure of Foreign Aid', Cato Journal 29, no. 3 (Fall 2009), pp. 379-382. hetps.//schold Jalure foreign-aid

Kingsley Chiedu Moghalu, Emerging Africa: How the Global Economy's 'Last Frontier' Can Prosper and Matter (London: Penguin Books, 2014), pp. 25-28.

William Easterly, The Tyranny of Experts: Economists, Dictators, and the Forgotten Rights of the Poor (New York Basic Books, 2013)

\section{Personal Response}

Is there a difference in donors as to whether they are governments or NGOs, or from which region they are from? Is aid from Asia handled any
differently, compared to aid from the West? differently, compared to aid from the West? II Normally, governments, as donors, work through their counterparts while NGOs engage directly
with aid recipients. Many NGOs are funded and with aid recipients. Many NGOs are funded and
utilised by donor governments as NGOs can provide convenience and efficiency for governments. Bilateral donors also partner with UN aid agencies given latter's expertise.

OECD has guidelines for its members, while non OECD donors have their own approach. Western countries focuses on physical infrastructure projects. However, what is most lacking, I believe, is the third 'pillar' of development relative to human capital, namely the 'mind-set change' approach. Aids from Asia are not handled particularly differently.

0

Embassy of the Republic of Korea 